\title{
Technoeconomic Evaluation of Recent Process Improvements in Production of Sugar and High- Value Lignin Co-Products via Two-Stage Cu- Catalyzed Alkaline-Oxidative Pretreatment
}

\section{Zhaoyang Yuan}

Michigan State University

Bryan D. Bals

Michigan Biotechnology Institute

Eric L. Hegg

Michigan State University

David B. Hodge ( $\sim$ david.hodge3@montana.edu )

Montana State University Bozeman https://orcid.org/0000-0002-9313-941X

\section{Research}

Keywords: Technoeconomic, Alkaline-Oxidative, $\mathrm{H} 2 \mathrm{O} 2$

Posted Date: November 15th, 2021

DOI: https://doi.org/10.21203/rs.3.rs-1040446/v1

License: (c) (1) This work is licensed under a Creative Commons Attribution 4.0 International License.

Read Full License 


\section{Abstract \\ Background}

A lignocellulose-to-biofuel biorefinery process that enables multiple product streams is recognized as a promising strategy to improve the economics of this biorefinery and to accelerate technology commercialization. We recently identified an innovative pretreatment technology that enables of the production of sugars at high yields while simultaneously generating a high-quality lignin stream that has been demonstrated as both a promising renewable polyol replacement for polyurethane applications and is highly susceptible to depolymerization into monomers. This technology comprises a two-stage pretreatment approach that includes an alkaline pre-extraction followed by a metal-catalyzed alkalineoxidative pretreatment. Our recent work demonstrated that $\mathrm{H}_{2} \mathrm{O}_{2}$ and $\mathrm{O}_{2}$ act synergistically as co-oxidants during the alkaline-oxidative pretreatment and could significantly reduce the pretreatment chemical input while maintaining high sugar yields, high lignin yields, and improvements in lignin usage.

\section{Results}

This study considers the economic impact of these advances and provides strategies that could lead to additional economic improvements for future commercialization. The results of the technoeconomic analysis (TEA) demonstrated that adding $\mathrm{O}_{2}$ as a co-oxidant at 50 psig for the alkaline-oxidative pretreatment and reducing the raw material input reduced the minimum fuel selling price from $\$ 1.08 / \mathrm{L}$ to $\$ 0.85 / L$, assuming recoverable lignin is used as a polyol replacement. If additional lignin can be recovered and sold as more valuable monomers, the minimum fuel selling price (MFSP) can be further reduced to $\$ 0.73 / \mathrm{L}$.

\section{Conclusions}

The present work demonstrated that high sugar and lignin yields combined with low raw material inputs and increasing the value of lignin could greatly increase the economic viability of a poplar-based biorefinery. Continued research on integrating sugar production with lignin valorization is thus warranted to confirm this economic potential as the technology matures.

\section{Introduction}

Substantial research has been directed at developing technologies to convert lignocellulosic biomass into renewable biofuels and biobased chemicals and materials, with the objective of facilitating the transition of the petroleum-based economy into a bioeconomy [1-3]. One focus has been the deconstruction of structural polysaccharides in the cell walls of plants to monomeric sugars that can be further processed through biological, catalytic, or chemical conversion. To achieve this goal, a wide range of chemical, physical, and biological biomass deconstruction/pretreatment technologies have been developed to 
improve the recovery of sugars by reducing the recalcitrance of the cell wall $[2,3]$. While significant progress has been achieved, economic challenges remain [4], and consequently, identifying approaches to reduce the process cost and/or improve the product value are of great importance for commercializing this biorefinery concept.

One promising approach is to produce co-products along with biofuels that can both improve the overall economics of the process and improve the overall carbon/mass efficiency of the process. Additionally, diversification of the product portfolio of lignocellulose-to-biofuels processes is widely recognized as an opportunity both to improve the economics of these processes and to buffer against market fluctuations. Lignin is the major non-polysaccharide structural component of lignocellulosic biomass at approximately $18-30 \%$ of the total dry mass weight and, as such, represents a promising source of reduced carbon for fuels and chemicals. While many biorefining concepts consider the use of process-modified lignins as a relatively low-value fuel to provide process heat and power [5-8], if key functionalities can be preserved or process modifications of the lignin are minimized, lignin can serve as a source of renewable aromatics for a diverse range of co-product applications. As one example, process-modified lignins can be utilized as a renewable bio-based polyol in the production of polyurethanes $[9,10]$, which has been shown to exhibit improved biodegradability compared to the petroleum-based polyurethanes [11, 12]. As another example, lignin can serve as the raw material for functionalized aromatic monomers such as vanillin, vanillic acid, syringic acid, syringaldehyde, and $p$-hydroxybenzoic acid, which can be used as platform chemicals [13-15]. Therefore, it is important to develop an understanding of these integrated economic models of integrated biorefineries that can partition both polysaccharides and lignins into fuels and chemical co-products, thereby improving their use in the production of sugars and lignin at a low cost and minimum usage of reagents.

Lignin chemical structures, properties, and utility in specific applications are a strong function of both the biomass source and prior processing history of the lignin [16-18]. Notably, lignins may undergo significant loss of utility due to repolymerization reactions when subjected to dilute acid pretreatment or delignification during Kraft pulping [19-22]. Consequently, biomass pretreatment or fractionation technologies may be economically compelling if they are capable of yielding both a clean sugar stream for the production of biofuels and lignins that can feed multiple co-product streams, while additionally providing flexibility in the partitioning of lignin between co-product streams. Our prior work with two-stage alkaline pre-extraction followed by copper-catalyzed alkaline hydrogen peroxide pretreatment (Cu-AHP) demonstrated the potential of this technology for producing fermentable sugars at high yields for biofuel production while simultaneously recovering high quality lignin as a co-product. We recently demonstrated nearly complete deconstruction of structural polysaccharides to monosaccharides while simultaneously solubilizing over $70 \%$ of the original lignin [23]. Importantly, this prior work also demonstrated that the recovered lignins are more suitable in co-product applications than other process-derived lignins (e.g., Kraft lignin). Firstly, we demonstrated that Cu-AHP lignins were suitable as an aromatic polyol in polyurethane resin applications and $30 \%$ more reactive with isocyanate than Kraft lignin (on the basis of equivalent aliphatic hydroxyl content) [23], making it an ideal aromatic polyol substitute in polyurethanes. Likewise, the lignins from this process could be depolymerized into potentially high-value aromatic 
monomers at high yields $(>30 \%)$, which is significantly higher than yields achievable from many other process-derived lignins [16, 24-26].

This present study analyzed the economic impact of these advances, considering multiple uses for lignin to determine the impact on the minimum fuel selling price (MFSP) using experimental data for different hybrid poplar processing scenarios published in our prior work [23]. The technoeconomic analysis (TEA) was performed using an Excel-based model derived from the National Renewable Energy Laboratory (NREL) model for catalytic upgrading of sugars to hydrocarbons [27]. Scenarios varying lignin utilization were analyzed to determine strategies to further improve MFSP that included the impact of varying the percentage of the lignin stream diverted from energy production to valorization into high-value products such as renewable polyols for polyurethane coating applications and depolymerization to aromatic monomers. Finally, a sensitivity analysis was conducted to identify parameters with the most significant impacts on economic performance.

\section{Methods}

\section{Modeling Overview}

The technoeconomic model of the two-stage alkaline-oxidative pretreatment for a cellulosic biorefinery with a capacity of 2000 metric tons per day was developed using Microsoft Excel 2016 based on the NREL model for a process of converting corn stover to hydrocarbons [27]. In brief, our model employed hybrid poplar rather than corn stover and replaced the pretreatment module of the NREL model with the two-stage pretreatment comprising alkaline pre-extraction followed by Cu-AHP delignification described in our prior work [23]. All pieces of equipment, material streams, and major energy flows were accounted for in this model. Moreover, a material balance was used to modify the sizing of all downstream operations, and this resizing was used to determine all capital, material, and energy costs. The general scheme for mass flows for the two-stage alkaline-oxidative pretreatment with a process description and experimental process parameters is summarized in Figure 1. The process model considered all unit operations required to transform the biomass into monomeric sugars, mainly glucose and xylose. Those operations were grouped into five major discrete units, namely feedstock preparation, alkaline pre-extraction, alkalineoxidative pretreatment, lignin recovery and valorization, and enzymatic hydrolysis (Fig. 1). All models were based on experimental results for pretreatment process performance (biomass compositions and response to pretreatment and enzymatic hydrolysis) that were published previously [23].

\section{Modeling Unit}

\section{Feedstock Preparation Unit}

The feedstock for the modeled process was debarked hybrid poplar (Populus nigra var. charkoviensis $\times$ caudina cv. NE-19) with a composition of $45.5 \%$ glucan, $15.8 \%$ combined xylan, galactan, and mannan, $22.3 \%$ Klason lignin, $2.5 \%$ acid-soluble lignin, and $0.85 \%$ ash [23]. Briefly, the harvested poplar was air-dried and debarked prior to delivery. The debarked logs were subjected to size reduction 
comprising of chipping and milling to prepare required-sized biomass for the biorefinery. The biomass loss during the size reduction process was assumed to be $1 \%$, which was directed to the boiler for combustion for energy/heat. The cost of poplar used in the model includes the costs of feedstock, the feedstock preparation process, and the delivery of processed feedstock.

\section{Pretreatment Unit}

The two-stage pretreatment process was fully described in our earlier work [23]. Briefly, sodium hydroxide $(\mathrm{NaOH})$ and the prepared biomass feedstock were mixed in the pretreatment reactor at $10 \% \mathrm{NaOH}$ loading on biomass (w/w based on the dry weight of the biomass) and 10\% (w/v) consistency at either $90^{\circ} \mathrm{C}$ or $120^{\circ} \mathrm{C}$ for $1 \mathrm{~h}$. The chemical composition of the alkaline pre-extracted poplar biomass was based on previously determined values (Additional file 1: Table S1). For alkaline pre-extraction, the reactor was modeled as a vertical agitated vessel with a conical bottom and screw discharge and entry with a maximum size of $1000 \mathrm{~m}^{3}$. Following alkaline pre-extraction, the solid biomass was subjected to the second-stage alkaline-oxidative pretreatment, during which $\mathrm{NaOH}, \mathrm{CuSO}_{4}, 2,2 \rrbracket$-bipyridine (bpy), hydrogen peroxide $\left(\mathrm{H}_{2} \mathrm{O}_{2}\right)$, and oxygen $\left(\mathrm{O}_{2}\right)$ were added to the pre-extracted poplar for further fractionation. For the alkaline-oxidative pretreatment step, the reactor was modeled as two smaller vertical reactors in sequence, each approximately $680 \mathrm{~m}^{3}$, in which the $\mathrm{O}_{2}$ and reagents could be mixed with the pre-digested biomass. Pretreatment conditions and reagent loadings are shown in Table 1. Once all material was mixed, the slurry was digested for $12 \mathrm{~h}$ in vertical reactors with a maximum size of $3000 \mathrm{~m}^{3}$. In establishing the economic model, the biomass chips were assumed to be transported to the refinery at a cost of $\$ 55 /$ tonne dry weight. The chips were optionally milled to $5 \mathrm{~mm}$ particle size via a hammer mill at an electrical cost of $40 \mathrm{kWh} /$ tonne [28]. After alkaline-oxidative pretreatment, a solid-liquid separation was performed via a pneumatic filter press with the same cost assumptions as Davis et al. [27] scaled to the amount of solids recovered. Following filtration, the liquid streams were subjected to lignin recovery through acidification to $\mathrm{pH} 2$ with $\mathrm{H}_{2} \mathrm{SO}_{4}$ and filtration through a standard filter press. 
Table 1

Conditions assessed for the second-stage alkalineoxidative pretreatment

\begin{tabular}{|ll|}
\hline \multicolumn{2}{|l|}{ Alkaline-oxidative pretreatment Parameter } \\
\hline Temperature $\left({ }^{\circ} \mathrm{C}\right)$ & 80 \\
\hline Time (h) & 12 \\
\hline $\mathrm{CuSO}_{4}$ dosage (wt. \%) & 0.159 \\
\hline 2,2'-bipyridine (bpy) dosage (wt. \%) & 0.156 \\
\hline $\mathrm{NaOH}$ loading (wt. \%) & 10 \\
\hline $\mathrm{H}_{2} \mathrm{O}_{2}$ loading (wt. \%) & $0-8$ \\
\hline $\mathrm{O}_{2}$ pressure (psig) & 50 \\
\hline
\end{tabular}

\section{Processing Liquor Recovery Unit}

After the first alkaline pre-extraction stage, the solubilized lignin was separated and recovered through sequential acidification to $\mathrm{pH} 2$ with $72 \%(\mathrm{w} / \mathrm{w}) \mathrm{H}_{2} \mathrm{SO}_{4}$ and filtration through a standard filter press. In addition, we have demonstrated the dissolved carbohydrates in the alkaline pre-extraction liquor can also be directly recovered by adding the liquor into the enzymatic hydrolysis step [29]. As utilizing both the preextraction stream and the alkaline-oxidative pretreatment stream would result in an enzymatic hydrolysis stream that is too dilute to be viable, the remaining liquor was assumed to be concentrated via evaporation, with capital and energy costs obtained from Davis et al. [27] and scaled to the amount of water evaporated. Note that this was not performed at lab scale and thus remains to be tested. In the labscale work, the lignin precipitate was washed 2 times with aqueous $\mathrm{H}_{2} \mathrm{SO}_{4}(\mathrm{pH} 2.0)$, and finally washed one time with cold deionized water. For the purposes of this TEA, the downstream lignin purification activities were not modeled. It was assumed that the lignin would be sold in a crude state with the price reflecting the fact that further processing may be needed. Similarly, the dissolved lignin and carbohydrates in the liquor obtained from the second alkaline-oxidative pretreatment stage were recovered in the same process. Carbohydrates solubilized from both the alkaline pre-extraction step and the second stage alkaline-oxidative $\mathrm{O}_{2}$-Cu-AHP process were assumed to be utilized for enzymatic hydrolysis.

\section{Enzymatic Hydrolysis Unit}

In this process, the solid fraction, dissolved carbohydrates, water, and enzyme were mixed. An enzyme loading of $15 \mathrm{mg}$ protein/g glucan (consisting of CTec3 and HTec3 at a protein ratio of 1:1) was used for this study. The enzymes were assumed to be purchased at a cost of $\$ 5 / \mathrm{kg}$ protein (Table 2). Sugar yields were assumed to be identical to those in the laboratory experiments. The resulting sugars were modeled to be combined with purchased hydrogen $\left(\mathrm{H}_{2}\right)$ and catalytically upgraded to hydrocarbon biofuel, while 
the residual enzymatic hydrolyzed solids were combusted to generate energy for the biorefinery plant (Fig. 1). All equipment downstream of the fermentation were modeled from Davis et al. [27] and scaled appropriately to the size of the streams.

\section{Lignin Recovery and Valorization Unit}

The lignin-rich solids obtained from the processing liquors (both alkaline pre-extraction and alkalineoxidative pretreatment liquors) were considered as a source of polyols for use in polyurethane coatings applications or used for the production of aromatic monomers. However, the system boundary of this model does not include upgrading of lignin to final products. Multiple scenarios were tested with lignin. As a base case, the solubilized lignin was assumed to be sold as-is at $\$ 0.80$ per $\mathrm{kg}$, approximately half the market value of polyols used for polyurethane [30]. Currently, only acid precipitation has been tested as a means of isolating the lignin from both stages of the pretreatment process, which recovered $79-80 \%$ and $31-35 \%$ of solubilized lignin during the first-stage alkaline pre-extraction and the second-stage alkaline-oxidative pretreatment, respectively. Thus, two scenarios were tested: one in which only the lignin recovered via acid precipitation is sold (with the remainder burned for energy), and one in which all solubilized lignin is assumed to be recoverable. In addition, a portion of the lignin could be depolymerized to monomers, which could be sold at a higher value than as a polyol substitute. Given the limited knowledge surrounding the value of these monomers and the cost of upgrading the lignin, we assumed a flat value of $\$ 2.00 / \mathrm{kg}$ for lignin to be upgraded to monomers.

\section{Process Economic Analysis}

Table 1 summarizes the economic process parameters used in this study. This study evaluates the economics for a biorefinery with a throughput of 2000 dry metric tons (MT) of biomass per day and operated for 350 days per year and $24 \mathrm{~h} /$ day as in the prior NREL technoeconomic model [27]. Process equipment units were then sized based on operating conditions and mass and energy balance from the process model. In addition to the equipment purchase cost, an installation cost for each piece of process equipment was also included as installed cost. For example, the use of $\mathrm{O}_{2}$ as a co-oxidant required increased thickness of the reactor to tolerant high pressure. Thus, the installed cost was higher than that of the reactor used for reaction without $\mathrm{O}_{2}$, which was considered in the economic model (Table 2). In addition, the $\mathrm{O}_{2}$ was assumed to be generated from air, with cost data derived from the National Energy Technology Laboratory and scaled appropriately [31]. When $\mathrm{O}_{2}$ was used as a co-oxidant, the pretreatment reaction vessels were rated for $0.7 \mathrm{MPa}$ to account for the $\mathrm{O}_{2}$ pressure and elevated temperature. Vessel thickness was adjusted based on design equations from Peters et al. [32] and the cost of the vessel adjusted accordingly. The alkaline pre-extraction vessels were assumed to be rated for $0.3 \mathrm{MPa}$ if performed at $90^{\circ} \mathrm{C}$ and $0.5 \mathrm{MPa}$ if performed at $120^{\circ} \mathrm{C}$. Once all capital and operating costs were obtained, the minimum fuel selling price (MFSP) was obtained by fixing the 30-year net present value of the biorefinery to $\$ 0$ using a $10 \%$ internal rate of return. All assumptions for calculating this rate of return are the same as in the NREL model [27]. A summary of the key cost and operational assumptions for economic analysis are shown in Table 2. 
Table 2

Cost and operation assumptions and parameters used in the economic model

\section{Raw Material Costs}

Hybrid Poplar

Glycoside hydrolase Enzymes

$\mathrm{NaOH}$

$\mathrm{CuSO}_{4}$

2,2'-Bipyridine

$\mathrm{H}_{2} \mathrm{O}_{2}$

Product Selling Price

Hydrocarbon Biofuel

Lignin Selling Price

Biorefinery Operation

Biorefinery Throughput

Biorefinery Operation

Installed Capital Costs

Pre-extraction Reactor $\left(90^{\circ} \mathrm{C}\right)$

Pre-extraction Reactor $\left(120^{\circ} \mathrm{C}\right)$

Pretreatment Reactor $\left(\mathrm{no}_{2}\right)$

Pretreatment Reactor (with $\mathrm{O}_{2}$ )

Material Handling

Oxygenation

Pretreatment Concentration and Lignin Separation

Enzymatic Hydrolysis

Catalytic Conversion

Wastewater Treatment

Storage

Boiler

Utilities
$\$ 55 /$ dry metric ton

$\$ 5 / \mathrm{kg}$ protein

$\$ 149 /$ metric ton

$\$ 1.50 / \mathrm{kg}$

$\$ 30 / \mathrm{kg}$

$\$ 1.00 / \mathrm{kg}$

MFSP, set by solution to economic model

$\$ 0.80 / \mathrm{kg}$

83.3 dry metric tonne/hr

$8400 \mathrm{hr} /$ year

$\$ 2,133,000$

$\$ 2,879,000$

$\$ 15,746,000$

$\$ 28,157,000$

$\$ 4,500,000$

$\$ 9,590,000$

$\$ 62,893,000$

$\$ 65,682,000$

$\$ 101,617,000$

$\$ 78,951,000$

$\$ 5,544,000$

$\$ 39,386,000$

$\$ 4,192,000$ 


\section{Sensitivity and Uncertainty Analysis}

Given the inherent uncertainty in economic modeling, a sensitivity analysis was performed around factors identified as being either significant to the final MFSP or to the factors considered the most uncertain. Factors were adjusted upward or downward by $25 \%$ and the model re-run to determine its impact on the MFSP. Given the high uncertainty of the value of lignin as a monomer, this value was adjusted by $50 \%$. The factors chosen and the low, medium, and high values (where applicable) are shown in Table 3.

Table 3

Assumptions for the sensitivity analysis

\begin{tabular}{|llll|}
\hline Factors & Low Values & Base Case & High Values \\
\hline Sugar usage & $\begin{array}{l}\text { Sugars from pre-extraction not } \\
\text { included }\end{array}$ & $\begin{array}{l}\text { All sugars } \\
\text { included }\end{array}$ & N/A \\
\hline Lignin value as a polyol & $\$ 0.60 / \mathrm{kg}$ lignin & $\$ 0.80 / \mathrm{kg}$ lignin & $\begin{array}{l}\$ 1.00 / \mathrm{kg} \\
\text { lignin }\end{array}$ \\
\hline Named monomer price & $\$ 1.00 / \mathrm{kg}$ & $\$ 2.00 / \mathrm{kg}$ & \\
\hline $\mathrm{H}_{2} \mathrm{O}_{2}$ price & $\$ 750 /$ tonne & $\$ 1000 /$ tonne & $\$ 1250 /$ tonne \\
\hline $\begin{array}{l}\text { Pretreatment vessel capital } \\
\text { cost }\end{array}$ & $-25 \%$ & $\$ 31.71 \mathrm{MM}$ & $+25 \%$ \\
\hline Oxygen usage & $28.1 \mathrm{~g} / \mathrm{kg}$ poplar & $37.5 \mathrm{~g} / \mathrm{kg}$ & $\begin{array}{l}46.9 \mathrm{~g} / \mathrm{kg} \\
\text { poplar }\end{array}$ \\
\hline Operation cost & & poplar & \\
\hline
\end{tabular}

\section{Results And Discussion}

\section{Overview of Biomass Conversion Pathway}

The overall processing strategy for biomass conversion to fuels and chemicals assessed in this work is presented in Fig. 2. The two-stage alkaline pre-extraction followed by alkaline-oxidative pretreatment method is used to fractionate lignocellulose biomass into various lignin and sugar streams for downstream conversion. As shown in Fig. 2, this approach provides the flexibility to accommodate shifting market conditions. It does this by yielding several lignin products that can target multiple markets, altering the properties of the lignin, and varying the partitioning of lignin into the three intermediate product pools, or target molecules. One key set of target molecules includes phenolic acid and aldehyde monomers (vanillin, vanillic acid, syringaldehyde, syringic acid, and others) that can be directed towards high-value, low-volume markets (e.g., flavor and fragrance compounds) as well as towards medium-value, high-volume bulk aromatic chemical markets with applications that could include bio-based polymers [33-35]. A second class of target molecules is highly functionalized oligomeric lignins that have potential in resin formulations for bio-based polyurethane coatings. 
Unlike hydrogenation/reductive approaches to lignin depolymerization or conversion whereby alcohols, aldehydes, carboxylates, and aromatics are reduced and deoxygenated, oxidations can preserve and generate oxygen-containing functional groups (i.e., vanillin, vanillic acid, syringaldehyde, syringic acid, acetosyringone, acetovallinone). While the oxygen content of biomass-derived compounds is a negative for fuels applications, oxygen-containing groups are useful for providing chemical functionality and reactivity for use as platform chemicals or as reactive aromatic polymers that can be incorporated into polyurethane resin formulations to increase their bio-based content.

\section{Capital and Operating Costs}

Table 4 shows the material balance for the eight pretreatment conditions assessed in this study based on our prior experimental study [23]. As shown, varying the pretreatment conditions impacted both the monomeric sugar (glucose and xylose) yields and the extent of delignification, thereby affecting the yields of biofuels and lignin-based products (polyols and aromatic monomers). With increasing pretreatment severity (i.e., temperature and oxidant loading), the yields of products (monomeric sugars and lignin) were increased (Additional file 1: Table S3). However, increasing the pretreatment severity also resulted in increased capital and operating costs. Therefore, an optimum balance between the process costs and the product yields needed to be identified with the technoeconomic model. 
Table 4

Material balance of the studied conditions (feedstock: 2000 MT per day)

\section{Experimental Reaction Conditions $^{\mathrm{a}}$}

Product Generation (MT/day)

\begin{tabular}{|lllll|}
\cline { 2 - 5 } & Glucose & Xylose & $\begin{array}{l}\text { Total Solubilized } \\
\text { Lignin }\end{array}$ & $\begin{array}{l}\text { Total Precipitated } \\
\text { Lignin }\end{array}$ \\
\hline $120^{\circ} \mathrm{C}-\mathrm{Cu}-\mathrm{AHP} 8 \% \mathrm{H}_{2} \mathrm{O}_{2}$ & 822.1 & 320.1 & 225.1 & 135.2 \\
\hline $120^{\circ} \mathrm{C}-\mathrm{Cu}(\mathrm{bppy})+\mathrm{O}_{2}$ & 808.0 & 309.9 & 222.4 & 133.8 \\
\hline $120^{\circ} \mathrm{C}-\mathrm{Cu}-\mathrm{AHP} 8 \% \mathrm{H}_{2} \mathrm{O}_{2}+\mathrm{O}_{2}$ & 984.8 & 359.1 & 333.5 & 160.8 \\
\hline $120^{\circ} \mathrm{C}-\mathrm{Cu}-\mathrm{AHP} 6 \% \mathrm{H}_{2} \mathrm{O}_{2}+\mathrm{O}_{2}$ & 975.6 & 359.1 & 323.9 & 160.4 \\
\hline $120^{\circ} \mathrm{C}-\mathrm{Cu}-\mathrm{AHP} 4 \% \mathrm{H}_{2} \mathrm{O}_{2}+\mathrm{O}_{2}$ & 959.8 & 359.1 & 307.4 & 158.2 \\
\hline $120^{\circ} \mathrm{C}-\mathrm{Cu}-\mathrm{AHP} 2 \% \mathrm{H}_{2} \mathrm{O}_{2}+\mathrm{O}_{2}$ & 946.9 & 359.1 & 297.8 & 156.1 \\
\hline $90^{\circ} \mathrm{C}-\mathrm{Cu}-\mathrm{AHP} 8 \% \mathrm{H}_{2} \mathrm{O}_{2}$ & 653.6 & 256.0 & 167.5 & 85.9 \\
\hline $90^{\circ} \mathrm{C}-\mathrm{Cu}-\mathrm{AHP} 4 \% \mathrm{H}_{2} \mathrm{O}_{2}+\mathrm{O}_{2}$ & 778.0 & 289.4 & 216.9 & 98.0 \\
\hline
\end{tabular}

MT: metric ton

${ }^{\mathrm{a}} 120^{\circ} \mathrm{C}$ and $90^{\circ} \mathrm{C}$ : alkaline pre-extraction step conducted at $120^{\circ} \mathrm{C}$ and $90^{\circ} \mathrm{C}$, respectively. Cu-AHP $\mathrm{H}_{2} \mathrm{O}_{2}$ : Cu-AHP pretreatment performed at $80^{\circ} \mathrm{C}$; $\mathrm{Cu}(\mathrm{bpy})+\mathrm{O}_{2}: \mathrm{Cu}$ (bpy)-catalyzed alkaline-oxidative pretreatment with 50 psig $\mathrm{O}_{2}$ as the only oxidant; $\mathrm{Cu}-\mathrm{AHP} \mathrm{H}_{2} \mathrm{O}_{2}+\mathrm{O}_{2}: \mathrm{O}_{2}$-enhanced Cu-AHP pretreatment $\left(50\right.$ psig $\left.\mathrm{O}_{2}\right)$. Values are expressed as average \pm standard deviation of triplicate experiments

Figure 3a shows the total capital costs for all eight pretreatment conditions modeled in this study. The use of both $\mathrm{H}_{2} \mathrm{O}_{2}$ and $\mathrm{O}_{2}$ as co-oxidants during the alkaline-oxidative pretreatment stage increased the capital cost compared to the alkaline-oxidative pretreatment with $\mathrm{H}_{2} \mathrm{O}_{2}$ only. Moreover, the case with alkaline pre-extraction performed at $90^{\circ} \mathrm{C}$ and alkaline-oxidative pretreatment performed with only $8 \%$ $\mathrm{H}_{2} \mathrm{O}_{2}$ had the lowest total capital cost (\$20.1 million), while the case with alkaline pre-extraction performed at $120^{\circ} \mathrm{C}$ and the alkaline-oxidative pretreatment with $8 \% \mathrm{H}_{2} \mathrm{O}_{2}$ and 50 psig $\mathrm{O}_{2}$ had the highest total capital cost (\$42.2 million). This could be attributed to the higher cost reactor; the addition of 50 psig $\mathrm{O}_{2}$ requires a much thicker vessel than the case without using $\mathrm{O}_{2}$.

Figure $3 \mathrm{~b}$ displays the operating costs for the eight pretreatment conditions. As shown, under the same alkaline pre-extraction temperature $\left(120^{\circ} \mathrm{C}\right)$, using $\mathrm{O}_{2}$ in addition to $\mathrm{H}_{2} \mathrm{O}_{2}$ during the alkaline-oxidative pretreatment stage only slightly increases operating costs. $\mathrm{O}_{2}$ was assumed to be recovered from air on site, during which only the electricity was used as a contributor to the operating cost. In contrast, reducing 
$\mathrm{H}_{2} \mathrm{O}_{2}$ utilization from 8-2\% reduced operating costs by $\$ 42$ million/year due to the relatively high cost of purchasing $\mathrm{H}_{2} \mathrm{O}_{2}(\$ 1 / \mathrm{kg})$; this could lead to a considerable decrease in MFSP. To probe further the operating cost, the individual contributors to the operating cost were also investigated (Additional file 1: Table S4). Moreover, when using the solubilized lignin for high-value products instead of burning for energy, the required electricity increased for the cases that solubilized more lignin during the pretreatment process; this also increased the operating cost.

\section{Minimum Fuel Selling Price (MFSP)}

Figure 4 shows the MFSP $(\$ / L)$ for the eight pretreatment conditions considered in this study. Two scenarios are presented for the MFSP. In the first scenario, the soluble lignin that is not precipitated is burned for energy, while in the second scenario, the soluble lignin in the Cu-AHP extract that is not precipitated is assumed to be recoverable and sold at the same price as the precipitated lignin $(\$ 0.80 / \mathrm{kg})$. The cost of pretreatment chemicals had a large influence on the MFSP, accounting for $40 \%$ of the total operating costs for the base case of a $120^{\circ} \mathrm{C}$ alkaline pre-extraction followed by an alkaline oxidative $\mathrm{Cu}$ AHP pretreatment with $8 \% \mathrm{H}_{2} \mathrm{O}_{2}\left(120^{\circ} \mathrm{C}-\mathrm{Cu}-\mathrm{AHP} 8 \% \mathrm{H}_{2} \mathrm{O}_{2}\right)$. If we assumed that the acid-soluble lignin was not recoverable, the MFSP using $\mathrm{H}_{2} \mathrm{O}_{2}$ as the only oxidant $\left[\left(120^{\circ} \mathrm{C}-\mathrm{Cu}-\mathrm{AHP} 8 \% \mathrm{H}_{2} \mathrm{O}_{2}\right)\right.$ and $\left(90^{\circ} \mathrm{C}-\right.$ Cu-AHP $8 \% \mathrm{H}_{2} \mathrm{O}_{2}$ )] ) was between $\$ 1.32 / \mathrm{L}$ and $\$ 1.08 / \mathrm{L}$ depending on the temperature of the alkaline preextraction stage. Conversely, when $\mathrm{O}_{2}$ was used as a co-oxidant and the $\mathrm{H}_{2} \mathrm{O}_{2}$ loading was reduced from $8-2 \%$, the MFSP decreased to between $\$ 0.94 / \mathrm{L}$ to $\$ 0.85 / \mathrm{L}$. This is because this sizable reduction in pretreatment chemical usage did not result in a corresponding large reduction in sugar yields (Table 2; [23]). Eliminating the $\mathrm{H}_{2} \mathrm{O}_{2}$ entirely led to slight increase in MFSP due to an appreciable reduction in both the sugar and lignin yields (Table 2; [23]). Importantly, if the acid-soluble lignin can be recovered for valueadded products, then the MFSP can be reduced by an additional $\$ 0.10 / \mathrm{L}$ (down to $\$ 0.77 / \mathrm{L}$ ) if $\mathrm{O}_{2}$ is employed as a co-oxidant during the Cu-AHP process $\left(120^{\circ} \mathrm{C}-\mathrm{Cu}\right.$-AHP $\left.2 \% \mathrm{H}_{2} \mathrm{O}_{2}+\mathrm{O}_{2}\right)$. The use of $\mathrm{O}_{2}$ as a co-oxidant increased the amount of lignin solubilized during pretreatment, but a larger proportion of this lignin was acid soluble. Thus, the difference in MFSP between the two assumptions (all solubilized lignin is recoverable versus only precipitated lignin) was greater when $\mathrm{O}_{2}$ was employed as a co-oxidant.

The TEA indicates that the overall MFSP can be reduced by nearly $40 \%$ by using $\mathrm{O}_{2}$ as a co-oxidant in the $\mathrm{Cu}$-AHP process relative to the $\mathrm{Cu}$-AHP pretreatment using $\mathrm{H}_{2} \mathrm{O}_{2}$ only. This is due both to a decrease in pretreatment operating cost (due to a reduction in $\mathrm{H}_{2} \mathrm{O}_{2}$ loading) and to an increase in both glucose and lignin yield. The primary tradeoff for oxygen utilization is a modest increase in electricity usage to generate the oxygen as well as an increase in capital costs (the oxygen production unit is assumed to cost $\$ 9.7$ million, while the cost of increasing the pressure rating of the pretreatment vessel is $\$ 12.4$ million). Despite these costs, the added capital cost only increased $\sim 6 \%$ (Fig. 2) and therefore did not greatly impact the MFSP. From the results in Fig. 3, pretreatment conditions of alkaline pre-extraction $\left(120^{\circ} \mathrm{C}\right)$ and alkaline-oxidative pretreatment $\left(2 \% \mathrm{H}_{2} \mathrm{O}_{2}\right.$ and $\left.\mathrm{O}_{2}\right)$ were selected as the base case for further analysis. Moreover, a detailed list of contributors to the MFSP of the selected base case $\left(2 \% \mathrm{H}_{2} \mathrm{O}_{2}\right.$ and $\mathrm{O}_{2}$ ) was also provided (Additional file 1: Table S4). 


\section{Effect of Lignin Valorization on MFSP}

The above analysis assumed only lignin that was solubilized and recoverable by acid precipitation could be utilized as a polyol substitute. Multiple other scenarios were also considered: (1) no lignin was recovered for additional value as a worst case scenario, (2) $16 \%$ of the recovered lignin (based on results obtained from lignin depolymerization following the method of sequential Bobbitt's salt oxidation followed by formic-acid catalyzed depolymerization process [23]) could be sold as monomers, increasing its value to $\$ 2.00 / \mathrm{kg}$, while the remainder of the precipitated lignin was sold as a polyol substitute, (3) the solubilized but not precipitated lignin could also be recovered and sold as a polyol substitute $(\$ 0.80 / \mathrm{kg})$, (4) $16 \%$ of all solubilized lignin (including the non-precipitated portion) was sold as monomers (with the remainder as a polyol substitute), and (5) the precipitated lignin was sold as a polyol substitute, while $48 \%$ of the non-precipitated lignin was sold as monomers (Fig. 5).

Importantly, if the acid-soluble lignin can be recovered for value-added products, then the MFSP can be reduced by an additional $\$ 0.07 / \mathrm{L}$ (down to $\$ 0.78 / \mathrm{L}$ ) if $\mathrm{O}_{2}$ is employed as a co-oxidant during the $\mathrm{Cu}-\mathrm{AHP}$ process $\left(120^{\circ} \mathrm{C}-\mathrm{Cu}\right.$-AHP $\left.2 \% \mathrm{H}_{2} \mathrm{O}_{2}+\mathrm{O}_{2}\right)$. As noted above, the use of $\mathrm{O}_{2}$ as a co-oxidant increased the amount of lignin solubilized during pretreatment, but a larger proportion of this lignin was acid soluble. Thus, a strategy to recovery this soluble lignin will be important to further optimize this process due to the presence of oxygen. Likewise, if the value of the lignin can be increased by conversion to aromatic monomers, the MFSP can be reduced further to $\$ 0.73 / \mathrm{L}$. This is due solely to increased value of lignin, as it increases from $12-26 \%$ of the total revenue of the biorefinery. An intermediate approach, in which $48 \%$ of the soluble lignin can be recovered and sold as high value monomers, also significantly reduces the cost to $\$ 0.74 / \mathrm{L}$. If lignin is not recovered as a co-product, the MFSP is $\$ 1.03 / \mathrm{L}$, indicating the importance of lignin recovery during Cu-AHP pretreatment.

Significant advances have been made to reduce the input costs of copper-catalyzed alkaline hydrogen peroxide pretreatment while simultaneously maintaining high sugar yields [23, 36, 37]. Despite this, the operating costs for pretreatment were still high at approximately $\$ 71$ million/year for a 2000 ton/day facility (Fig. 4) or $\$ 97 /$ ton biomass, resulting in a $\$ 1.03 / \mathrm{L}$ MFSP if no lignin was recovered as a valueadded product. This decreased to $\$ 0.85 / \mathrm{L}$ if precipitated lignin was recovered as a polyol substitute and $\$ 0.78 / \mathrm{L}$ if all soluble lignin could be recovered as a polyol substitute. While the technology to produce polyurethane products from lignin is relatively well understood, the possibility of producing monomers can reduce the selling price further down to $\$ 0.73 / \mathrm{L}$. While challenges currently remain to commercializing this technology, it demonstrates that further selling price reductions are possible as improvements in lignin valorization continue. Thus, the combination of reduced pretreatment inputs while maintaining high sugar and lignin solubilization and improved usage of recovered lignin is instrumental in obtaining economically competitive biofuels.

\section{Sensitivity Analysis}


Understanding the impact of key parameters on the MFSP is of great importance to developing this technology further. Sensitivity of the MFSP with the sequential two-stage alkaline pre-extraction and alkaline-oxidative pretreatment of hybrid poplar (the selected base case) is summarized in Figure 6, in which the capital and operating costs were also included. Yield of both sugar and lignin had the highest impact on the final biofuel selling price, indicating the importance of recovering all of the solubilized material. Likewise, the value of the lignin, used either in polyurethane applications or as lignin monomers, also resulted in large changes in the biofuel selling price. This indicates that revenue, rather than the individual costs of the refinery, drives the economics of the process. Each of the cost drivers selected, namely hydrogen peroxide cost, pretreatment capital cost, oxidation pressure, and total oxygen usage had relatively minimal impact on the final selling price of the fuel. This analysis provides evidence that, if the high yields and potentially high value for lignin can be maintained as the process is scaled to more industrially relevant conditions, the potential for economic value will remain even if costs are greater than initially anticipated.

The results further indicate that it is of great importance to include the lignin properties and valorization strategies when establishing TEA models for biorefinery. This is because the lignin value has a significant impact on the MFSP (based on the scenarios we studied). To include the lignin value in the model, there are several methods to be considered: (1) Purifying lignin for the various applications in order to design downstream separations, (2) recycling or treating any waste streams generated from these separations, and (3) drying and packaging of the final lignin product. Synergies may be found if the final product (such as polyurethane) is produced at the same location. Further laboratory optimization of lignin separations and purification would also be required.

\section{Conclusions}

Cu-AHP is promising technology to improve the production of biofuels from lignocellulose, and this economic assessment illustrates the importance of considering high value co-products when assessing these technologies. The pretreatment process described herein demonstrated high sugar and lignin yields while reducing the raw material input in the pretreatment, thereby yielding biofuel at a cost as low as $\$ 0.85 / \mathrm{L}$. In addition to the high yields, diversification of the lignin products into higher value products has

potential to reduce the fuel costs even further to $\$ 0.73 / \mathrm{L}$. Further research is thus warranted on improving and integrating the pretreatment and lignin valorization technologies, moving both of them to a more commercially ready state. Modeling this integration as the technology continues to progress will also be instrumental in ensuring the economic feasibility of the process.

\section{Declarations}

\section{Ethics Approval and Consent to Participate}

Not applicable. 


\section{Consent for Publication}

Not applicable.

\section{Competing Interests}

The authors declare the following competing financial interest(s): E.L.H., Z.Y., D.B.H., and B.D.B. are listed as inventors on a related pending patent application (Economical Methods for Performing Oxidative Catalytic Pretreatment of Plant Biomass Using a Homogeneous Catalyst System); US Publication No.: US $2020 / 0332376 \mathrm{~A} 1$. As holders of this patent, we may benefit financially from advances in the technology discussed in this article.

\section{Funding}

This work was funded by the U.S. Department of Energy (DOE) EERE under Contract No. DE-EE0008148.

\section{Authors' Contributions}

ZY performed experiments in all areas of pre-extraction, pretreatment, and enzymatic hydrolysis, and helped write the manuscript. BB established the technoeconomic model and performed technoeconomic analysis. DBH and ELH helped design pretreatment experiments, interpret the results, and edit the manuscript. All authors read and approved the final manuscript.

\section{Acknowledgements}

Not applicable.

\section{Availability of Data and Material}

The datasets used and/or analyzed during the current study are available from the corresponding authors on reasonable request.

\section{References}

1. Pinales-Márquez CD, Rodríguez-Jasso RM, Araújo RG, Loredo-Treviño A, Nabarlatz D, Gullón B, Ruiz HA. Circular bioeconomy and integrated biorefinery in the production of xylooligosaccharides from lignocellulosic biomass: a review. Ind Crops Prod. 2021;162:113274.

2. Soltanian S, Aghbashlo M, Almasi F, Hosseinzadeh-Bandbafha H, Nizami AS, Ok YS, Lam SS, Tabatabaei M. A critical review of the effects of pretreatment methods on the exergetic aspects of lignocellulosic biofuels. Energy Conver Manag. 2020;212:112792.

3. Yoo CG, Meng X, Pu Y, Ragauskas AJ. The critical role of lignin in lignocellulosic biomass conversion and recent pretreatment strategies: A comprehensive review. Bioresour Technol. 2020;301:122784. 
4. Raud M, Kikas T, Sippula O, Shurpali NJ. Potentials and challenges in lignocellulosic biofuel production technology. Renew Sustain Energy Rev. 2019;111:44-56.

5. Humbird D, Davis R, TaoHumbird L, Kinchin C, Hsu D, Aden A, Schoen P, Lukas J, Olthof B, Worley M, Sexton D. Process design and economics for biochemical conversion of lignocellulosic biomass to ethanol: dilute-acid pretreatment and enzymatic hydrolysis of corn stover. National Renewable Energy Laboratory (NREL), No. NREL/TP-5100-47764. Golden, CO (United States); 2011.

6. Ou L, Kim H, Kelley S, Park S, Impacts of feedstock properties on the process economics of fastpyrolysis biorefineries. Biofuels Bioprod Biorefin. 2018;12(3):442-452 (2018).

7. Sudarsanam P, Duolikun T, Babu PS, Rokhum L, Johan MR. Recent developments in selective catalytic conversion of lignin into aromatics and their derivatives. Biomass Convers Biorefin. 2019;10:873-883.

8. Zhang R, Maltari R, Guo M, Kontro J, Eronen A, Repo T. Facile synthesis of vanillin from fractionated Kraft lignin. Ind Crop Prod. 2020;145:112095.

9. Alinejad M, Henry C, Nikafshar S, Gondaliya A, Bagheri S, Chen N, Singh SK, Hodge DB, Nejad M. Lignin-based polyurethanes: Opportunities for bio-based foams, elastomers, coatings and adhesives. Polymers. 2019;11(7):1202.

10. Bajwa DS, Pourhashem G, Ullah AH, Bajwa SG. A concise review of current lignin production, applications, products and their environmental impact. Ind Crops Prod. 2019;139:111526.

11. Wang HM, Yuan TQ, Song GY, Sun RC. Advanced and versatile lignin-derived biodegradable composite film materials toward a sustainable world. Green Chem. 2021;23:3790-3817.

12. Zhang Y, Wang J, Fang X, Liao J, Zhou X, Zhou S, Bai F, Peng S. High solid content production of environmentally benign ultra-thin lignin-based polyurethane films: plasticization and degradation. Polymer. 2019;178:121572.

13. Bourbiaux D, Pu J, Rataboul F, Djakovitch L, Geantet C, Laurenti D. Reductive or oxidative catalytic lignin depolymerization: an overview of recent advances. Catalysis Today. 2021;373:24-37.

14. Chio C, Sain M, Qin W. Lignin utilization: A review of lignin depolymerization from various aspects. Renew Sustain Energy Rev. 2019;107:232-249.

15. Schutyser W, Kruger JS, Robinson AM, Katahira R, Brandner DG, Cleveland NS, Mittal A, Peterson DJ, Meilan R, Román-Leshkov Y, Beckham GT. Revisiting alkaline aerobic lignin oxidation. Green Chem. 2018;20(16):3828-3844.

16. Das A, Rahimi A, Ulbrich A, Alherech M, Motagamwala AH, Bhalla A, da Costa Sousa L, Balan V, Dumesic JA, Hegg EL, Dale BE. Lignin conversion to low-molecular-weight aromatics via an aerobic oxidation-hydrolysis sequence: comparison of different lignin sources. ACS Sustain Chem Eng. 2018;6(3):3367-3374.

17. Ragauskas AJ, Beckham GT, Biddy MJ, Chandra R, Chen F, Davis MF, Davison BH, Dixon RA, Gilna P, Keller M, Langan, P. Lignin valorization: improving lignin processing in the biorefinery. Science. 2014;344(6185):1246843. 
18. Upton BM, Kasko, AM. Strategies for the conversion of lignin to high-value polymeric materials: Review and perspective. Chem Rev. 2016;116(4):2275-2306.

19. Crestini $C$, Lange H, Sette M, Argyropoulos DS. On the structure of softwood kraft lignin. Green Chem. 2017;19(17):4104-4121.

20. Lancefield CS, Rashid GM, Bouxin F, Wasak A, Tu WC, Hallett J, Zein S, Rodríguez J, Jackson SD, Westwood NJ, Bugg TD. Investigation of the chemocatalytic and biocatalytic valorization of a range of different lignin preparations: the importance of $\beta-0-4$ content. ACS Sustain Chem Eng. 2016;4(12):6921-6930.

21. Rinaldi R, Jastrzebski R, Clough MT, Ralph J, Kennema M, Bruijnincx PCA, Weckhuysen BM. Paving the way for lignin valorisation: recent advances in bioengineering, biorefining and catalysis. Angew. Chem Int Ed. 2016;55(29):8164-8215.

22. Sannigrahi P, Kim DH, Jung S, Ragauskas A. Pseudo-lignin and pretreatment chemistry. Energy Environ Sci. 2011;4(4):1306-1310.

23. Yuan Z, Klinger GE, Nikafshar S, Cui Y, Fang Z, Alherech M, Goes S, Anson C, Singh SK, Bals B, Hodge DB, Nejad M, Stahl SS, Hegg EL. Effective biomass fractionation through oxygen-enhanced alkalineoxidative pretreatment. ACS Sustain Chem Eng. 2021;9:1118-1127.

24. Bhalla A, Bansal N, Pattathil S, Li M, Shen W, Particka CA, Karlen SD, Phongpreecha T, Semaan RR, Gonzales-Vigil E, Ralph J. Engineered lignin in poplar biomass facilitates Cu-catalyzed alkalineoxidative pretreatment. ACS Sustain Chem Eng. 2018;6(3):2932-2941.

25. Rahimi A, Ulbrich A, Coon JJ, Stahl, SS, 2014. Formic-acid-induced depolymerization of oxidized lignin to aromatics. Nature, 515(7526), pp. 249-252.

26. Bhalla A, Cai CM, Xu F, Singh SK, Bansal N, Phongpreecha T, Dutta T, Foster CE, Kumar R, Simmons BA, Singh S. Performance of three delignifying pretreatments on hardwoods: hydrolysis yields, comprehensive mass balances, and lignin properties. Biotechnol Biofuels. 2019;12(1):1-5.

27. Davis R, Tao L, Scarlata C, Tan ECD, Ross J, Lukas J, Sexton D. Process design and economics for the conversion of lignocellulosic biomass to hydrocarbons: dilute-acid and enzymatic deconstruction of biomass to sugars and catalytic conversion of sugars to hydrocarbons. Golden, NREL, 2015. p. TP-5100-62498.

28. Liu Y, Wang J, Wolcott MP. Assessing the specific energy consumption and physical properties of comminuted Douglas-fir chips for bioconversion. Ind Crops Prod. 2016;94:394-400.

29. Bhalla A, Bansal N, Stoklosa RJ, Fountain M, Ralph J, Hodge DB, Hegg EL. Effective alkaline metalcatalyzed oxidative delignification of hybrid poplar. Biotechnol Biofuels. 2016;9(1):1-10.

30. Dessbesell L, Yuan Z, Hamilton S, Leitch M, Pulkki R, Xu C. Bio-based polymers production in a kraft lignin biorefinery: techno-economic assessment. Biofuels Bioprod Bioref. 2017;12:239-250.

31. James RE, Kearins D, Turner M, Woods M, Kuehn N, Zoelle A. Cost and performance baseline for fossil energy plants volume 1: Bituminous coal and natural gas to electricity. No. NETL-PUB-22638, NETL; 2019. 
32. Peters MS, Timmerhaus KD, West RE. Plant design and economics for chemical engineers (Vol. 4). New York: McGraw-Hill; 2003.

33. Cao Y, Chen SS, Zhang S, Ok YS, Matsagar BM, Wu KCW, Tsang DC. Advances in lignin valorization towards bio-based chemicals and fuels: lignin biorefinery. Bioresour Technol. 2019;291:121878.

34. Fache M, Boutevin B, Caillol, S. Vanillin production from lignin and its use as a renewable chemical. ACS Sustain Chem Eng. 2016;4(1):35-46.

35. Hocking, M. B. Vanillin: Synthetic flavoring from spent sulfite liquor. J Chem Educ. 1997;74:10551059.

36. Singh SK, Savoy AW, Yuan Z, Luo H, Stahl, SS, Hegg EL, Hodge DB. Integrated two-stage alkalineoxidative pretreatment of hybrid poplar. Part 1: impact of alkaline pre-extraction conditions on process performance and lignin properties. Ind Eng Chem Res. 2019;58(35):15989-15999.

37. Yuan Z, Singh SK, Bals B, Hodge DB, Hegg EL. Integrated two-stage alkaline-oxidative pretreatment of hybrid poplar. Part 2: impact of Cu-catalyzed alkaline hydrogen peroxide pretreatment conditions on process performance and economics. Ind. Eng. Chem. Res. 2019;58:16000-16008.

\section{Figures}

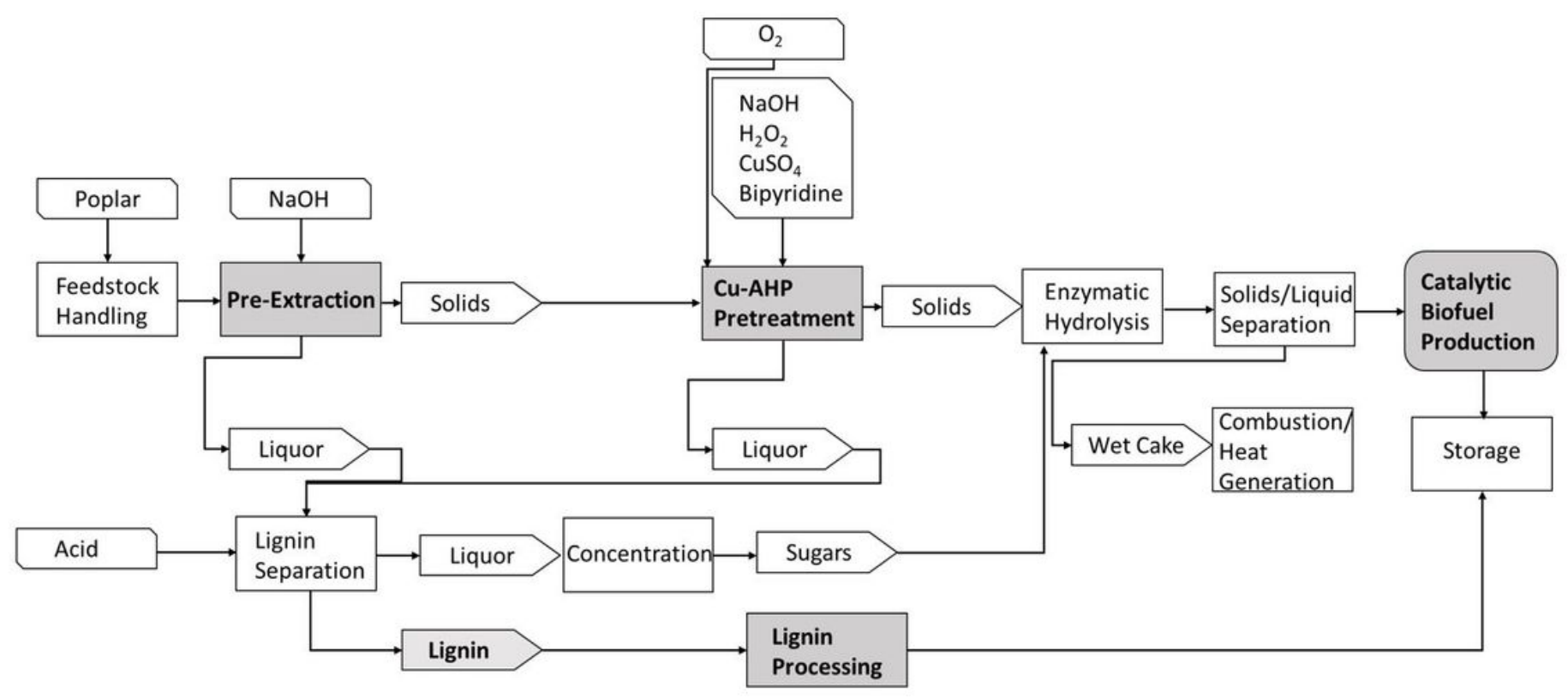

\section{Figure 1}

The flow diagram of the proposed two-stage alkaline pre-extraction/alkaline-oxidative pretreatment technology for poplar biorefinery 


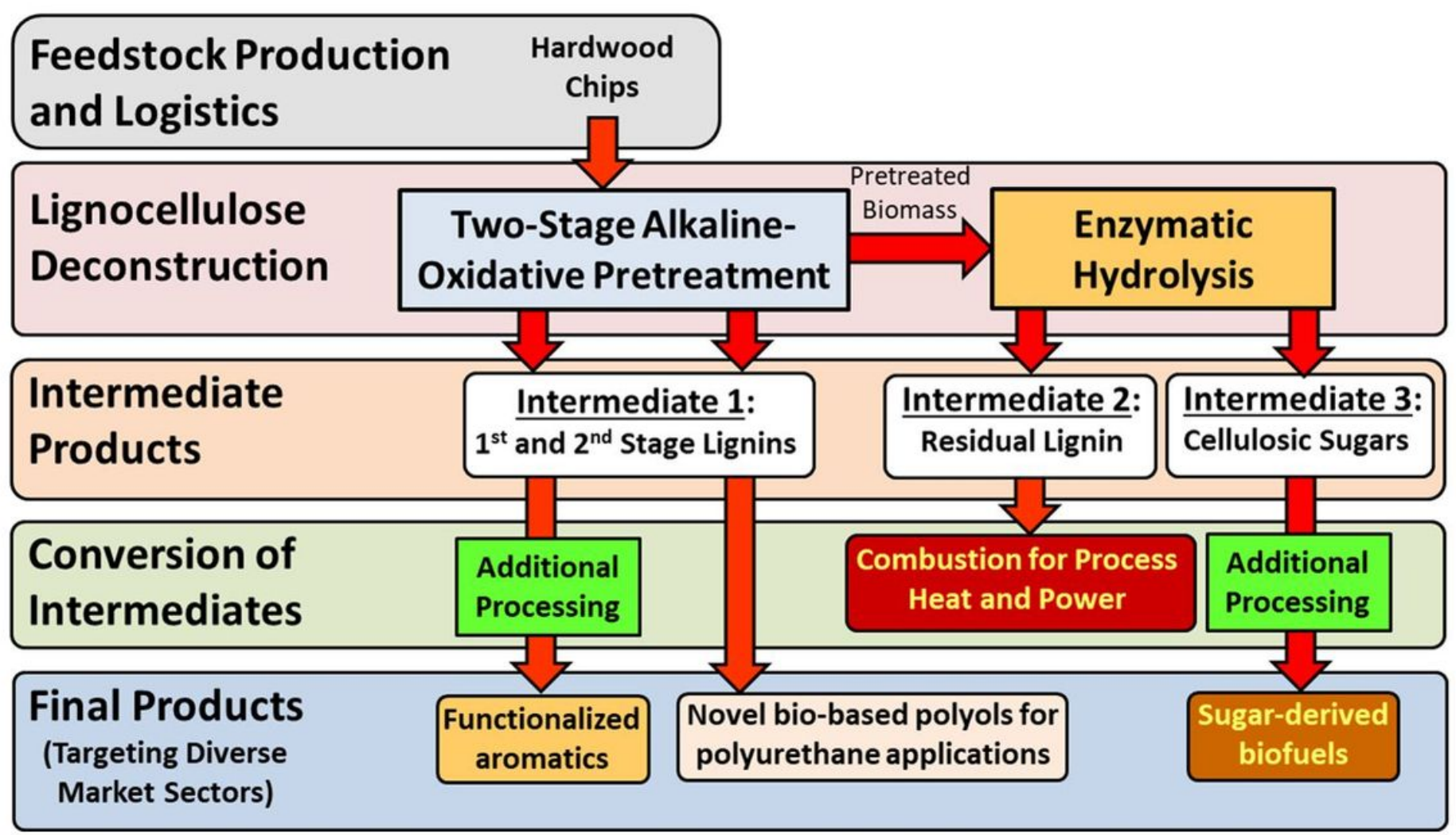

Figure 2

Overall biomass conversion pathway for generating lignin coproducts and sugar-derived hydrocarbon biofuels.
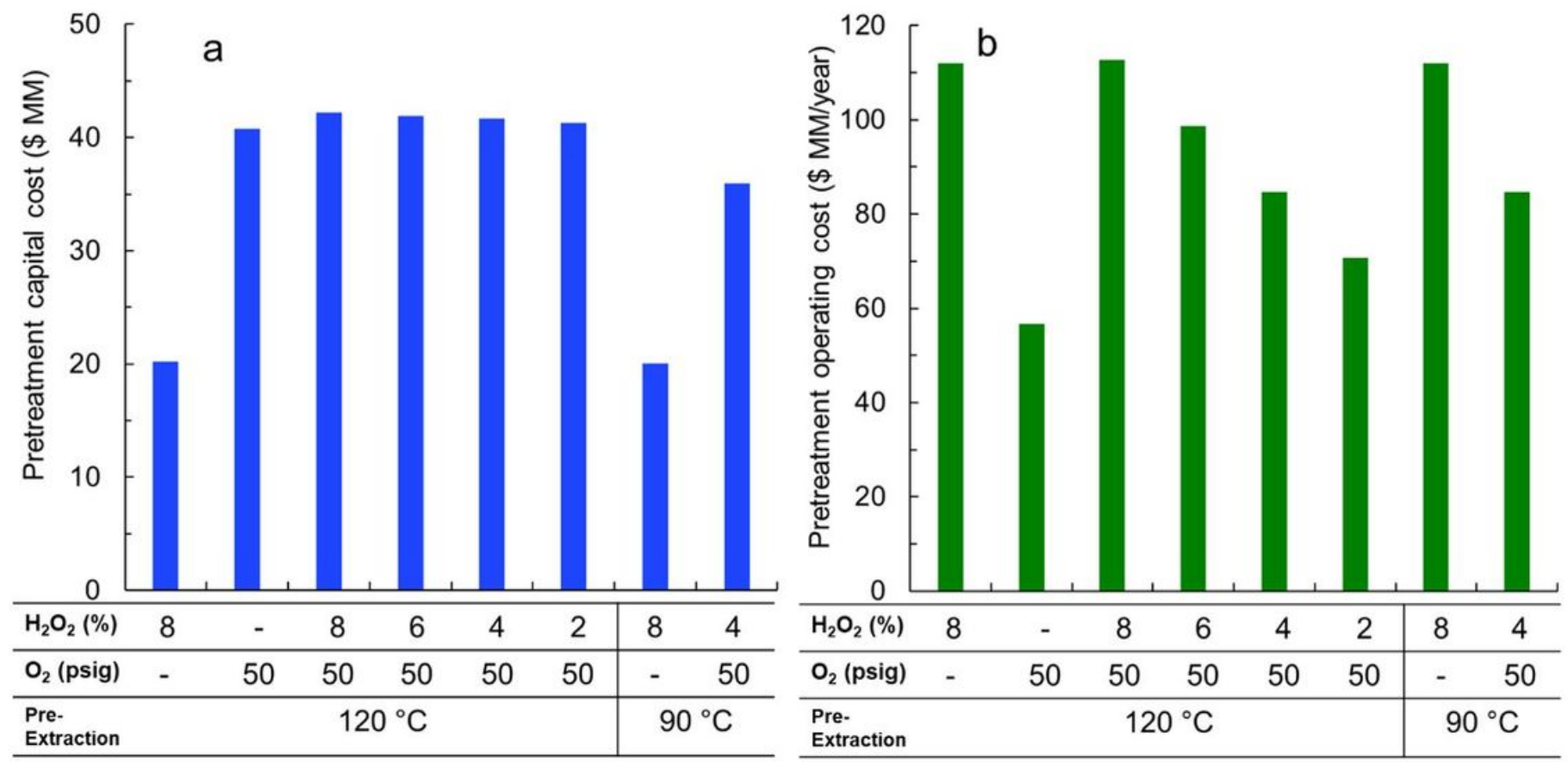
Figure 3

The pretreatment (a) capital cost and (b) operating cost of the poplar biorefinery

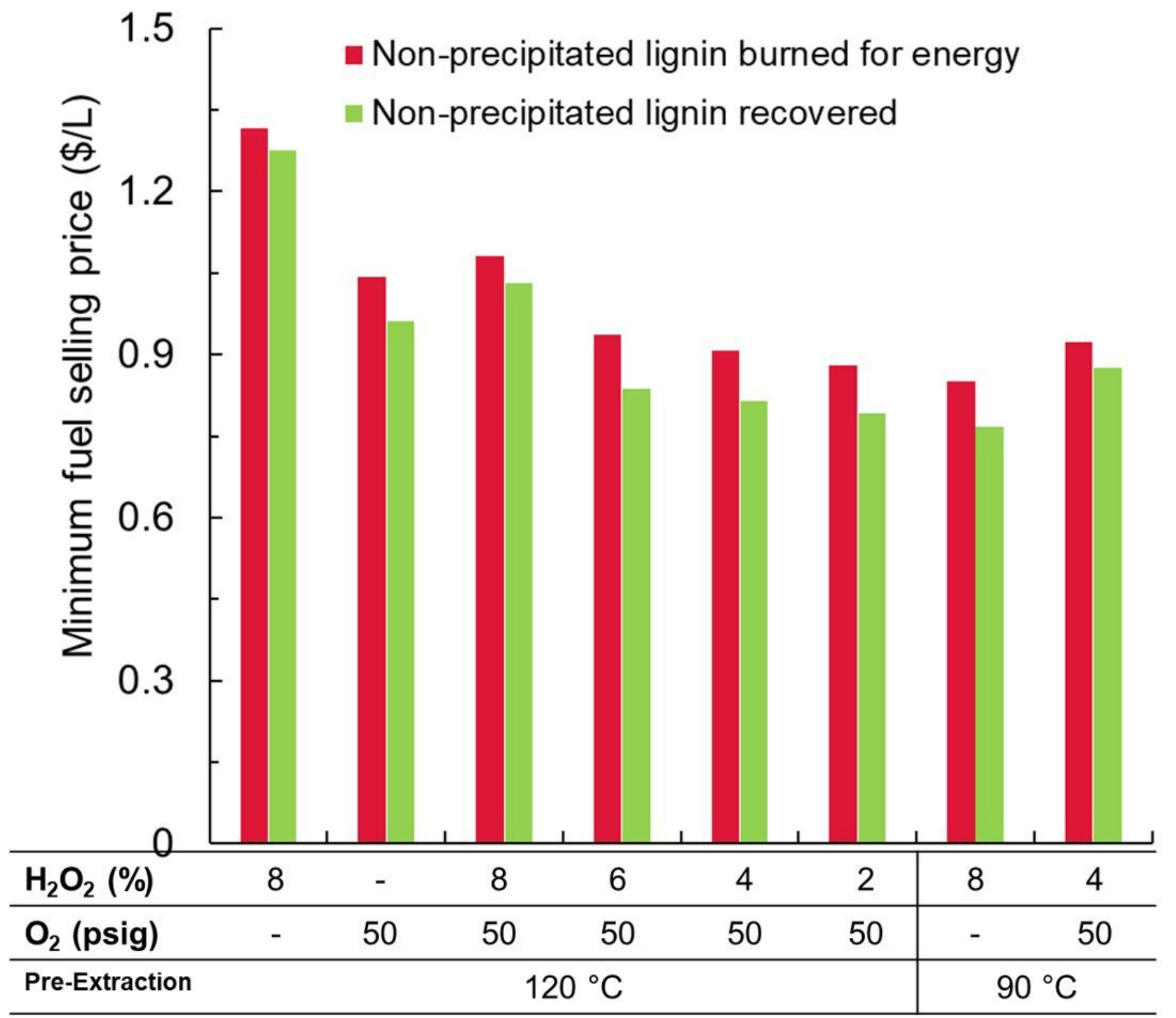

Figure 4

Minimum fuel selling price (MFSP) in $\$ / L$ for various Cu-AHP pretreatment conditions. MFSP is shown assuming non-precipitated soluble lignin in the extract of the second pretreatment stage is either burned for energy (red bar) or recovered for high value lignin products (green bar) 


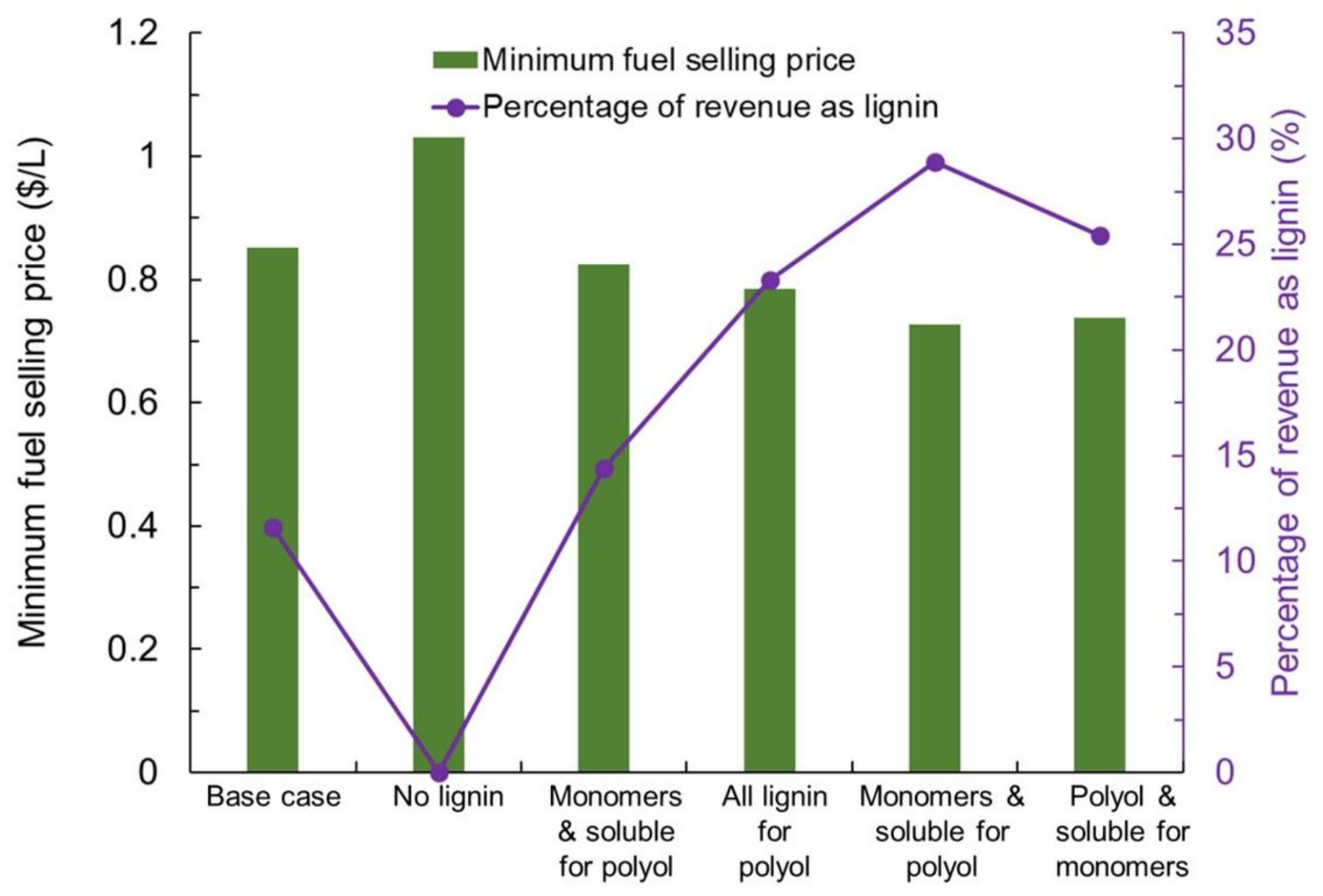

Figure 5

Impact of lignin recovery on minimum fuel selling price (MFSP) in $\$ / L$. The scenarios include (1) Base case - base case of precipitated lignin sold as a polyol replacement, (2) No lignin - no lignin recovered as value added material, (3) Monomers and soluble for polyol - $16 \%$ of precipitated lignin sold as high-value monomers with the remainder as a polyol replacement, (4) All lignin for polyol - All solubilized lignin sold as a polyol replacement, (5) Monomers and soluble for polyol - $16 \%$ of all solubilized lignin sold as highvalue monomers with the remainder as a polyol replacement, (6) Polyol and soluble for monomers - All precipitated lignin sold as a polyol replacement, while $48 \%$ of non-precipitated lignin sold as high-value monomers 


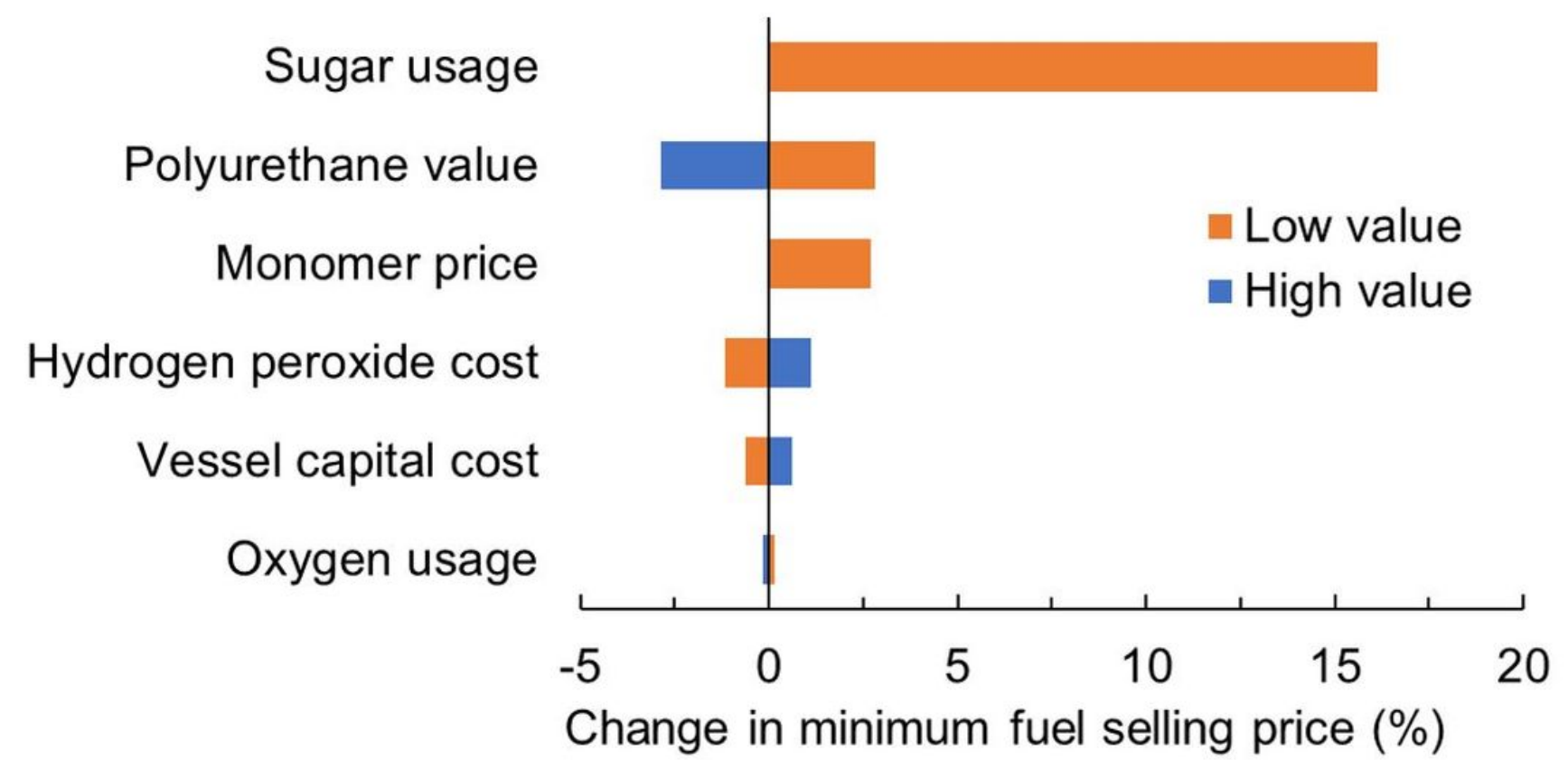

Figure 6

Sensitivity analysis results using scenarios for "low" and "high" outlined in Table 3

\section{Supplementary Files}

This is a list of supplementary files associated with this preprint. Click to download.

- Supportinglnformationv3.docx 